\title{
Prevalence of Schistosoma mansoni infection and the therapeutic efficacy of praziquantel among school children in Manna District, Jimma Zone, southwest Ethiopia
}

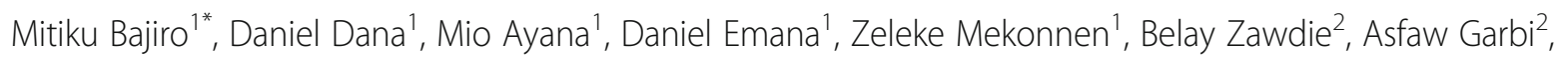
Ashenafi Kure ${ }^{3}$ and Ahmed Zeynudin ${ }^{1}$

\begin{abstract}
Background: Intestinal schistosomiasis is one of the neglected tropical parasitic diseases caused by Schistosoma mansoni. Currently, the control measures for the disease are mainly based on mass drug administration (MDA) with praziquantel (PZQ) targeting the school-age children. In Ethiopia, the potential foci for schistosomiasis and therapeutic efficacy of PZQ among school-age children remain poorly explored. Therefore, we determined both the prevalence and intensity of S. mansoni infection and the therapeutic efficacy of PZQ among school children in the Manna District (new foci for S. mansoni), Jimma Zone, southwest Ethiopia.

Methods: A cross-sectional study was conducted among the school children aged between 6 and 18 years in three primary schools in Manna district from March to April 2014. For diagnosis of S. mansoni, a single stool sample was obtained from each child and processed using single Kato Katz and examined under light microscopy. A questionnaire was used to collect demographic information of the school children participated in the study. School children excreting eggs of S. mansoni were administered with $40 \mathrm{mg} / \mathrm{kg}$ of PZQ and re-examined after three weeks post-treatment. The therapeutic efficacy of PZQ against S. mansoni was evaluated by means of cure rate and egg reduction rate.

Results: The overall prevalence of S. mansoni among the school children in the three primary schools in Manna District was $24.0 \%$. Higher prevalence was recorded for males $25.6 \%$ (61/238) than for females $22.5 \%$ (59/262). Majority (27.5 \%) of infection intensity was light with mean faecal egg count (FEC) of 202 eggs per gram (EPG). The therapeutic efficacy of PZQ at a dose of $40 \mathrm{mg} / \mathrm{kg}$ was highly efficient (cure rate of $99.1 \%$ and egg reduction rate of $99.9 \%$ ) among the school children in the three primary schools in Manna District.

Conclusions: The school children in the three primary schools of Manna District, Jimma Zone were at moderate risk of the morbidity caused by S. mansoni (prevalence $>10 \%$ and $<50 \%$ according to WHO threshold), and hence a biannual MDA with PZQ is required. PZQ available on the local market was found efficient and can be recommended for individual treatment in absence of MDA. The therapeutic efficacy of PZQ at $40 \mathrm{mg} / \mathrm{kg}$ against $\mathrm{S}$. mansoni was high in the study area.
\end{abstract}

Keywords: Schistosom mansoni, Kato-Katz, Praziquantel, Prevalence, Intensity, Cure rate, Egg reduction rate

\footnotetext{
* Correspondence: mitiku.bajiro@ju.edu.et

'Department of Medical Laboratory Sciences and Pathology, Jimma

University, Jimma, Ethiopia

Full list of author information is available at the end of the article
} 


\section{Background}

Intestinal schistosomiasis is a chronic parasitic disease caused by the trematode Schistosoma mansoni [1]. It is one of the neglected tropical parasitic diseases (NTDs) that causes severe morbidity and mortality among susceptible segments of the population. Its importance in terms of socioeconomic and public health in tropical and subtropical countries is high. In tropical developing countries about 779 million people were estimated to be at risk of infection (85\% in Africa), 207 million people are infected (> $97 \%$ in Africa) and 120 million people diseased (20 millions severely) [2, 3]. The annual mortality is estimated to be $15,000-280,000$ and 1.74.5 million disability adjusted life years are lost due to disease [4].

In Africa, 31 countries including Ethiopia share the great burden of schistosomiasis and millions of people have been suffering from the disease. The burden of schistosomiasis due to $S$. mansoni is 28.8 million in Nigeria, 19 million Tanzania, 15.2 million Ghana, 14.9 million Congo and 13.2 million Mozambique [3, 5]. In Ethiopia, the endemicity of intestinal schistosomiasis has long been established and estimates made in the early 1980s documented the number of people at risk of infection as 18 millions [6]. Several epidemiological studies indicate that intestinal schistosomiasis due to $S$. mansoni infection is widely distributed in different parts of Ethiopia with prevalences as high as $90 \%$ in school-age children [7].

Children in the developing countries live in areas with poor sanitation and most often spend time swimming or bathing in the water bodies contaminated with cercariae, the infective stages of schistosomes [8]. The hygiene and playing behavior in water bodies increases the risk of being infected by $S$. mansoni [9].

In the past, the preventive measures of schistosomiaiss largely focused on decreasing or interrupting transmission of the infection; however such measures have not been continued due to high operation cost/difficult implementation logistics [5]. The advent of inexpensive, efficacious and safe drugs has made chemotherapy the most cost-effective strategy thereby shifting control emphasis to disease control [10].

Oxamniquine, metrifonate and $P Z Q$ are the main drugs that have been used widely for control of schistosomiasis $[11,12]$. Among these anti-schistosomial drugs, PZQ is a broad spectrum drug that is effective against all species of Schistosoma. It is administered orally at a standard single dose of $40 \mathrm{mg} / \mathrm{kg}$ body weight and well tolerated. The side effects of the drug are mild and transient, and mostly related to the gastrointestinal tract effects, such as abdominal pain, nausea, vomiting, anorexia and diarrhea [13].

The efficacy of the drug is considered as sufficient when the cure rate (CR) is 60-90\% and egg reduction rate (ERR) is $>90 \%$, while facilitating patients' compliance especially among children $[14,15]$. Most of the time population treatment with $\mathrm{PZQ}$ produces $\mathrm{CR}$ of over $70 \%$. However, efficacy of treatment is influenced by a number of factors, such as the epidemiological situations and expands on the prevailing ecological conditions which may affect PZQ efficacy [16]. Efficacy of PZQ decreases with pre-treatment intensity of infection, number of pre-patent infections, diagnostic sensitivity and age of the treated individuals [17]. Moreover, poor drug quality and poor patient compliance may also negatively impact the effectiveness of the treatment, and even optimal timing at which treatment is evaluated also affects the outcome of the treatment [18].

Some studies conducted on the efficacy of PZQ against S. mansoni tested in Senegal reported CR as low as $18 \%$ raising the fear about the effectiveness of the drug [17]. However, there have been reports of $S$. mansoni resistance to PZQ from studies carried out in Egypt with failure to CR of $1.6 \%$ of those infected with $S$. mansoni in a Nile Delta village [19] and Kenya [20]. There are reports of low CR of $73.6 \%$ and ERR of $68.2 \%$ of PZQ in southern part of Ethiopia [21].

Our study area is not yet included in the epidemiological map of S. mansoni in Ethiopia and there are various reports providing evidence for parasite occurrence from the local health offices in the district. To the best of our knowledge, the epidemiology of S. mansoni and the therapeutic efficacy of PZQ have not been evaluated in the study area. Therefore, we determined the prevalence and intensity of $S$. mansoni infections and evaluated the therapeutic efficacy of PZQ against S. mansoni among the students of Manna District, Jimma Zone, southwest Ethiopia.

\section{Methods \\ Study area}

The study was conducted between March and April, 2014 among students of three primary schools namely Kore konjo, Wollo sefar and Saye odo in Mana District, Jimma Zone, Oromia Regional State, southwest, Ethiopia. The district is located $382 \mathrm{~km}$ away from the capital city of the country and $32 \mathrm{~km}$ away from Jimma Town in Jimma Zone. The district is located at an average altitude of about $1450 \mathrm{~m}$ above sea level. It is generally characterized by warm climate with a mean annual maximum temperature of $25{ }^{\circ} \mathrm{C}$ and a mean annual minimum temperature of $18{ }^{\circ} \mathrm{C}$. The annual rainfall ranges from 1138 to $1690 \mathrm{~mm}$ (Report document 2013/ 2014 of Jimma Zone administration). There are different water sources in the district which the population frequently used for domestic purposes and thus could be potential risk factor for infection with S. mansoni. 


\section{Study population}

Study populations were all school children enrolled in three primary schools of Manna district during study period. In each school, we stratified students according to three age groups (age 6-9 years, age 10-14 years and age 15-18 years). Five hundred students were screened to include at least $100 \mathrm{~S}$. mansoni-infected children at baseline screen based on WHO guideline and other literature for assessing the efficacy of anti-helminthic drugs against schistosomiasis and soil-transmitted helminthiases $[15,22]$.

\section{Sampling, study design and sample processing}

Simple random sampling technique was used to select the study participants based on their name list from their grades. School-based cross-sectional study was employed among school children of three primary schools in the Manna District. Stool samples were collected using dry, clean, labelled plastic containers. Kato-Katz thick smear was prepared from each stool sample for the detection and quantification of the eggs of S. mansoni and other soil-transmitted helminths (STH). The quantity of S. mansoni eggs was determined before and after treatments to determine the intensity of infection. Before the administration of $\mathrm{PZQ}$, all S. mansoni-infected students were provided biscuits and a cup of tea. Students who were treated with PZQ were followed by senior health officer and nurse for four hours and those who vomited within two hours after oral administration of the drug were excluded from the analysis.

\section{Praziquantel efficacy}

In post-treatment, a Kato-Katz thick smear was processed for each specimen to determine CR and ERR. Thus, efficacy of $40 \mathrm{mg} / \mathrm{kg}$ PZQ against $S$. mansoni was determined exactly on day 21 post-treatment and its efficacy were assessed as ERR (\%) as follows [15]:

$$
\begin{aligned}
\operatorname{ERR}(\%)= & 100 \\
& \times\left(1-\frac{\text { Arithmetic mean of egg counts at follow-up }}{\text { Arithmetic mean of egg counts at base line }}\right)
\end{aligned}
$$

The indicator of choice for drug efficacy is ERR. PZQ efficacy is satisfactory when ERR $\geq 90 \%$ with the reference value $\geq 90 \%$; doubtful when ERR is lower than the reference value by less than $10 \%$; and reduced if ERR is inferior by value of at least $10 \%$ points than the reference value [15].

\section{Data processing and analysis}

Data were coded, entered and cleaned by using EPIIFO. Data processing and analysis were carried out using SPSS version 20.0. CR was calculated as the ratio of the number of study participants who were negative after treatment to the number of study participants who were positive before treatment and who completed the study and ERR was calculated based on arithmetic means as described above. Infection intensity of S. mansoni was provided as geometric mean.

\section{Data quality assurance}

Refreshment training was given to data collectors and laboratory technicians about Kato-Katz smears by experienced personnel in the field. During data processing, the quality of data was assured by coding and double entry. From both positive and negative Kato-Katz smears, $10 \%$ were randomly selected and re-read by two independent medical laboratory experts who were blinded to the primary result. Moreover, fresh working solution of malachite-green was used routinely to maintain the quality of the smear.

\section{Results}

Socio-demographic characteristics of study participants A total of 500 students (238 males and 262 females) were involved from three primary schools selected in Manna District. The largest number of study participants, 379 (75.8 \%) was from the age group $10-14$ years.

\section{Prevalence and intensity of S. mansoni infection}

The overall prevalence of $S$. mansoni among students was $24 \%(120 / 500)$. The prevalence was $25.6 \%(61 / 238)$ and $22.5 \%(59 / 262)$ for the male and female students, respectively. The prevalence ranged from 7.6 to $41.4 \%$ among the schools with the highest prevalence $41.4 \%$ (41/99) in Kore Konjo School (Table 1). Majority of the infection intensity was classified as low with maximum EPG of 1848 (Fig. 1).

Table 1 Socio-demographic characteristics and prevalence of $S$. mansoni among school children in three primary schools of

\begin{tabular}{|c|c|c|c|}
\hline \multirow[t]{2}{*}{ Variables } & \multicolumn{2}{|c|}{ S. mansoni infection status } & \multirow[t]{2}{*}{ Total (\%) } \\
\hline & No. of positive (\%) & No. of negative (\%) & \\
\hline \multicolumn{4}{|l|}{ Sex } \\
\hline Male & $61(25.6)$ & $177(74.4)$ & $238(47.6)$ \\
\hline Female & $59(22.5)$ & $203(77.5)$ & $262(52.4)$ \\
\hline \multicolumn{4}{|l|}{ Age (years) } \\
\hline $6-9$ & $8(10.4)$ & 69 (89.6) & $77(15.4)$ \\
\hline $10-14$ & $98(26.1)$ & $278(73.9)$ & $376(75.2)$ \\
\hline $15-18$ & $14(29.8)$ & $33(70.2)$ & $47(9.4)$ \\
\hline \multicolumn{4}{|l|}{ Schools } \\
\hline Kore Konjo & $41(41.4)$ & $58(58.6)$ & 99 (19.8) \\
\hline Saye Odo & $66(28.6)$ & $165(71.4)$ & $231(46.2)$ \\
\hline Wollo Sefar & $13(7.6)$ & 157 (92.4) & 170 (34) \\
\hline
\end{tabular}
Manna District, Jimma Zone, southwest Ethiopia, 2014 


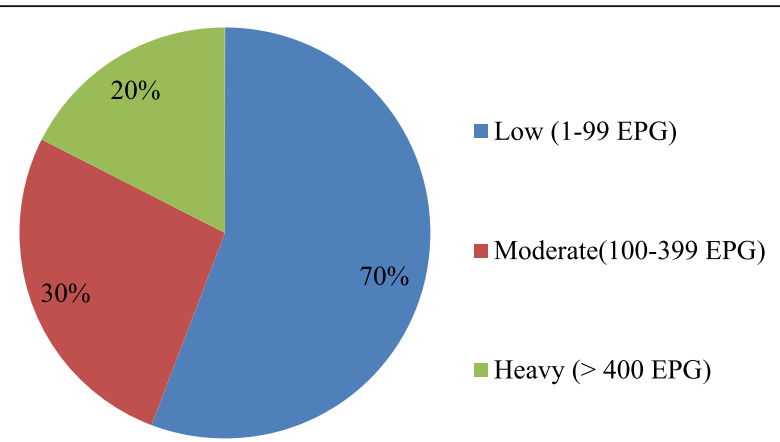

Fig. 1 Infection intensity of S. mansoni among school children in Manna District, Jimma Zone, southwest Ethiopia, 2014

\section{The therapeutic efficacy of praziquantel}

Among the study participants, 120 students were infected with $S$. mansoni and treated with $40 \mathrm{mg} / \mathrm{kg}$ PZQ at baseline screening. Of the 120 infected students, five were excluded from the analysis of PZQ efficacy after treatment with $40 \mathrm{mg} / \mathrm{kg}$ PZQ. Two of them vomited immediately after $20 \mathrm{~min}$ of drug administration and three refused to provide stool on the day of post-examination. The CR of PZQ against $S$. mansoni infected school children was $99.1 \%$. The ERR of $40 \mathrm{mg} / \mathrm{kg}$ PZQ was found to be 99.9 \%. ERR and CR had no statistically significant association with age of the school children and intensity S. mansoni infection $\left(\chi^{2}=1.74, P=0.424\right)$ (Table 2$)$.

\section{Discussion}

In the present study, the overall infection with $S$. mansoni among students of three primary schools in Manna District was $24 \%$. The therapeutic efficacy of PZQ at $40 \mathrm{mg} / \mathrm{kg}$ body weight against $S$. mansoni infection in the study area had 99.9 \% ERR and $99.1 \%$ CR. Majorities of infection intensities and the mean intensity of infection were low.

The prevalence rate in the present study was higher than those reported from Brazil (14.4\%), Nigeria (4.6\% and $12.6 \%)$ and Ghana (19.8 \%) [23-26]. Similarly, our findings were higher than two previous investigations conducted in Ethiopia including Tigray (5.95 \%) and Jimma $(2.1 \%)[27,28]$. The difference could be due to the study period and the method of laboratory diagnosis employed.

Table 2 Cure rate of PZQ against S. mansoni-infected school children in Manna District, Jimma Zone, southwest Ethiopia, 2014

\begin{tabular}{llllll}
\hline Age group & \multicolumn{2}{l}{ Cure rate $[n(\%)]$} & Total $[n(\%)]$ & $x^{2}$ & $P$-value \\
\cline { 2 - 4 } & $\begin{array}{l}\text { Cured } \\
{[n(\%)]}\end{array}$ & $\begin{array}{c}\text { Uncured } \\
{[n(\%)]}\end{array}$ & & & \\
\hline 6-9 years & $6(85.7)$ & $1(14.3)$ & $7(6.1)$ & 1.71 & 0.424 \\
10-14 years & $94(100)$ & 0 & $94(81.7)$ & & \\
15-19 years & $14(100)$ & 0 & $14(12.2)$ & & \\
Total & $114(99.1)$ & $1(0.9)$ & $115(100)$ & & \\
\hline
\end{tabular}

However, there are reports with higher prevalence from northwestern Tanzania (64.3\%) [29], and from southern Tigray (73.9 \%), Gonder (89.9 \%), Wondo Genet (74.9\%) and Wollega (67.6 \%) from Ethiopia [7, 21, 30-32]. The difference might be due to long time endemicity of the parasite in these study areas than the current emerging foci of our study area, the study design employed and ecological differences.

There is almost comparable report from Uganda (27.8 \%) [33] and other similar studies from Ethiopia including Mekelle (23.9 \%) [34] and southeast of Lake Langano (21.2 \%) [35].

The infection intensity in our study indicated low infection levels comparable with findings from Timuga and Waja from Tigray [36] and Mekelle City [34]. However, moderate infection intensities were reported from Wondo Genet [21] and Wollega [32] in Ethiopia. The difference may be explained by the frequency of students' contact with contaminated water-bodies and the burden of the adult worms hosted.

In the current study area, PZQ at $40 \mathrm{mg} / \mathrm{kg}$ had higher efficacy when compared with the reports from Senegal $(\mathrm{CR}=42.5 \%$ and $\mathrm{ERR}=70.7 \%)$ [37] and Nigeria $(C R=49.4 \%$ and $E R R=57.1 \%)$ [14]. This difference could be due to baseline infection intensity, duration of post-treatment, presence of immature stages of the parasite. Moreover, the new emergence of $S$. mansoni in the study area and the lack of previous exposure of school children to PZQ treatment as mass drug administration may contribute to the high efficacy. Previous efficacy study carried out at four weeks of post-treatment in northeast Ethiopia have reported lower CR (83.2 \%) [38]. Moreover, lower CR (73.6 \%) and ERR (68.2 \%) were reported from other studies undertaken in Wondo Genet, Ethiopia [21]. The difference might be due to the intensity of infection, brand of PZQ used, geographical variation, and the presence of immature stages of the parasite. On the contrary, the efficacy of PZQ at $40 \mathrm{mg} / \mathrm{kg}$ in the present study was higher compared to the study reported from Senegal (CR 18-38 \%) [39], Niger (ERR 55.2-60.2 \%) [40] eventhough the duration of post-treatment was similar to that of our study (three weeks). The variation of PZQ efficacy might be due to the infection intensity and geographical location.

The efficacy of PZQ at $40 \mathrm{mg} / \mathrm{kg}(\mathrm{CR}=99.1 \%$ and $\mathrm{ERR}=99.9 \%$ ) in the present study is almost comparable to the reports from South Africa $(C R=100 \%)$ [41], Sudan (CR 89-92.1\% and ERR 96.4-99.4 \%) [42], Egypt (CR 73.3-92.8 \%) [19] and Kenya (ERR = $92.6 \%$ [43]. Moreover, there are two reports from Ethiopia including Tigray, Timuga and Waja (CR of 93.44 and $88.9 \%$ ) [36], Wollega (CR of $80.9 \%$ and ERR of $99.5 \%$ ) [32], 
respectively, from Ethiopia at different post-treatment durations with comparable efficacy. Furthermore, the efficacy of PZQ at $40 \mathrm{mg} / \mathrm{kg}$ among students in present study is comparable with the findings from Senegal $(\mathrm{CR}=93 \%$ and $\mathrm{ERR}=90 \%)$ [18], Cameroon $(\mathrm{CR}=95.3 \%)$ [22], and Ethiopia $(C R=94 \%$ and $E R R=97 \%$ [44] with the same post-treatment duration.

\section{Conclusions}

The students in the three primary schools of Manna District, Jimma Zone were at moderate risk of the morbidity caused by S. mansoni (prevalence $>10 \%$ and $<50 \%$ according to WHO threshold), and hence a biannual MDA with PZQ is required. PZQ available on the local market revealed efficiency and can be recommended for individual treatment in absence of MDA. The infection intensity of $S$. mansoni among the school children in the current study was light. Among school children, the age group 10-14 years is the most affected. PZQ at $40 \mathrm{mg} / \mathrm{kg}$ has $99.9 \% \mathrm{ERR}$ and $99.1 \% \mathrm{CR}$. Therefore, the therapeutic efficacy of PZQ at $40 \mathrm{mg} / \mathrm{kg}$ against $S$. mansoni was high in the study area.

\section{Additional file}

Additional file 1: Consent form. (DOCX $16 \mathrm{~kb}$ )

\section{Abbreviations}

CR: Cure rate; ERR: Egg reduction rate; MDA: Mass drug administration; NTD: Neglected tropical diseases; PZQ: Praziquantel; STH: Soil-transmitted helminth; WHO: World Health Organization

\section{Acknowledgements}

The authors are grateful to Jimma University for financial support and VLIR-UOS (IUC-JU) for providing vehicle for transportation. We are grateful for School teachers, study participants, and their parents. The authors would also like to thank Dr. Bruno Levecke and Professor Josef Vercruysse for providing Kato-Katz kits, Laboratory reagents and PZQ for treating infected children. Additionally, we would like to thank the staff of Medical Laboratory Sciences, Jimma University, specifically Bizuwarke Sharew and Yesuf Seid for processing and examining the stool samples.

\section{Funding}

Financial support was given from Jimma University, College of Health Science, Research and postgraduate Office.

\section{Availability of data and materials}

Not applicable.

\section{Authors' contributions}

$M B, D D$ and $A Z$ designed study protocol, conducted survey, drafted the manuscript and analysis of the data. $M B, A Z, D D, Z M, M A, A K, D E, B Z$, and $A G$ conducted the survey and manuscript writing. MB, DD, AZ final manuscript writing. All authors have read and approved the final version of the manuscript.

\section{Authors' information}

$\mathrm{MB}$ is a lecturer of Medical Parasitology at Jimma University. AZ is an associate professor and PhD candidate at LMU, German and Jimma University. DD is a lecturer of Medical Parasitology and PhD candidate at Jimma University. MA is a lecturer of Medical Parasitology at Jimma University. ZM and DE are lecturers of molecular biology and Immunology at
Jimma University. BZ is a lecturer of biochemistry at Jimma University. AG is a lecturer of Anatomy at Jimma University. AK is a Chief Medical Parasitologist at Public Health Laboratory, South Nations Nationalities and People's Regional State Health Bureau.

\section{Competing interests}

The authors declare that they have no competing interests.

\section{Consent for publication}

Not applicable.

\section{Ethics approval and consent to participate}

Ethical approval was obtained from the Institutional Review Board (IRB) of Jimma University (HRPGC 118/2014) and a support letter was also obtained from the District Health Office. Only subjects whose parents/guardians signed written informed consent where included in the study (see Consent form in Additional file 1). Students excreting the egg of S. mansoni and STH were treated with PZQ 40 mg/kg (Distocide; EIPICO Egyptian International Pharmaceuticals Industries CO.A.R.E, Cairo, Egypt, under the license of SHIN POONG PHARMA.CO., LTD. SEOUL, KOREA, B.N./Mfg/Exp:1300371, 2013/1/

2016) and albendazole (400 mg), respectively. Both drugs were administered by experienced health officer and nurses. Students who vomited within two hours of PZQ administration were referred to the nearby Health Center for further treatment.

\section{Author details}

${ }^{1}$ Department of Medical Laboratory Sciences and Pathology, Jimma University, Jimma, Ethiopia. ${ }^{2}$ Departement of Biomedical Sciences, Jimma University, Jimma, Ethiopia. ${ }^{3}$ Public Health Laboratory, South Nations Nationalities and People's Regional State Health Bureau, Hawassa, Ethiopia.

Received: 6 January 2016 Accepted: 5 October 2016

Published online: 24 October 2016

\section{References}

1. Cheesbrough M. District laboratory practice in tropical countries. 2nd ed. Cambrdge: Cambridge University Press; 2009. p. 216-21. part 1.

2. Engels D, Chitsulo L, Montresor A, Savioli L. The global epidemiological situation of schistosomiasis and new approaches to control and research. Acta Trop. 2002;82(2):139-46.

3. Steinmann P, Keiser J, Bos R, Tanner M, Utizinger J. Schistosomiasis and water resources development: systematic review, meta-analysis, and estimates of people at risk. Lancet Infect Dis. 2006;6:411-25.

4. WHO. The world health report 2004: changing history, burden of disease in DALYs by cause, sex and mortality stratum in WHO regions, estimates for 2002. Geneva: World Health Organization; 2004.

5. WHO. Prevention and control of schistosomiasis and soil-transmitted helminthiasis: report of a WHO expert committee. WHO Tech Rep; 2002. p. 1-57.

6. Lo CT, Kloos H, Birrie H. The ecology of health and disease in Ethiopia. Addis Abeba: Report Ministy of Health; 1988. p. 196-213.

7. Worku L, Damte D, Endris M, Tesfa H, Aemero M. Schistosoma mansoni infection and associated determinant factors among school children in Sanja Town, Northwest Ethiopia. J Parasitol Res. 2014:1-8.

8. CDC. Parasite: schistosomiasis. 2012. http://www.cdc.gov/parasites/ schistosomiasis/

9. WHO. Schistosomiasis. 2012. http://www.who.int/mediacentre/factsheets/ fs115/en/index.html.

10. WHO. The control of schistosomiasis. Second report of the WHO expert committee. WHO technical report series 830; 1993. p. 1-86.

11. Cioli D, Pica-Mattoccia L, Archer S. Antischistosomal drugs: past, present .. future? Pharm Ther. 1995;68(1):35-85.

12. Utzinger J, Keiser J. Schistosomiasis and soil-transmitted helminthiasis: common drugs for treatment and control. Exp Opin Pharmacother. 2004; 5(2):263-85

13. Sabah AA, Fletcher C, Webbe G, Doenhoff MJ. Schistosoma mansoni: chemotherapy of infections of different ages. Exp Parasitol. 1986:61(3):294-303.

14. Utzinger J, N'Goran EK, N'dri A, Lengeler C, Tanner M. Efficacy of praziquantel against schistosoma mansoni with particular consideration for intensity of infection. Trop Med Int Health. 2000;5(11):771-8. 
15. WHO. Assessing the efficacy of anthelminthic drugs against schistosomiasis and soil-transmitted helminthiases, vol. 253. WHO Library Cataloguing-inPublication Data; 2013. p. 1-39.

16. Gryseels B, Polderman AM, Engels D. Experiences with the control of Schistosoma mansoni in two foci in central Africa. Mem Inst Oswaldo Cruz. 1992:4:187-94.

17. Gryseels B, Mbaye A, De vlas SJ, Stelma FF, Guisse F, Van Lieshout L, et al. Are poor responses to praziquantel for the treatment of Schistosoma mansoni infections in Senegal due to resistance? An overview of the evidence. Trop Med Int Health. 2001;6(11):864-73.

18. Tweyongyere R, Mawa PA, Kihembo M, Jones FM, Webb EL, Coses S, et al. Effect of praziquantel treatment of Schistosoma mansoni during pregnancy on immune responses to schistosome antigens among the offspring: results of a randomised, placebo-controlled trial. BMC Infect Dis. 2011;11(10):234.

19. Botros S, Sayed H, Amer N, El-Ghannam M, Bennett JL, Day TA. Current status of sensitivity to praziquantel in a focus of potential drug resistance in Egypt. Int J Parasitol. 2005;35(7):787-91.

20. Melman SD, Steinauer ML, Cunningham C, Kubatko LS, Mwangi IN, Wynn $N R$, et al. Reduced susceptibility to praziquantel among naturally occurring Kenyan isolates of Schistosoma mansoni. PLoS Negl Trop Dis. 2009;3(8):e504.

21. Erko B, Degarege A, Tadesse K, Mathiwos A, Legesse M. Efficacy and side effects of praziquantel in the treatment of schistosomaiss mansoni in school children in Shesha kebele elementary school, Wondo Genet, Southern Ethiopia. Asian Pac J Trop Biomed. 2012;4(1):235-39.

22. Tchuem Tchuente LA, Momo SC, Stothard JR, Rollinson D. Efficacy of praziquantel and reinfection patterns in single and mixed infection foci for intestinal and urogenital schistosomiasis in Cameroon. Acta Trop. 2013;128(2):275-83.

23. Anto F, Asoala V, Adjuik M, Anyorigiya T, Oduro A, Akazili J, et al. Water contact activities and prevalence of schistosomiasis infection among school-age children in communities along an irrigation scheme in rural northern Ghana. Bact Parasitol. 2013;4(4):2-6.

24. Banji B, Babadoko M, Mohammed G. Survey of schistosomiasis and other intestinal helminthiases among school-aged children in Agaie, Niger state, Nigeria. J Pharm Biomed Sci. 2012;15(7):1-5.

25. Barbosa CS, Favre TC, Wanderley TN, Callou AC, Pieri OS. Assessment of schistosomiasis, through school surveys, in the Forest Zone of Pernambuco, Brazil. Mem Inst Oswaldo Cruz. 2006:101(1):55-62.

26. Goselle NO, Anegbe D, Imandeh GN, Dakul DA, Onwuliri ACF, Abba OJ, et al. Schistosoma mansoni infections amongst school children in Jos, Nigeria. Sci World J. 2010;5(1):1-4

27. Tadesse D, Tsehaye A. Schistosomiasis mansoni among school children of different water source users in Tigray, northern Ethiopia. MEJS. 2010;2(1):49-60.

28. Yami A, Mamo Y, Kebede S. Prevalence and predictors of intestinal helminthiasis among school children in Jimma Zone. Ethiop J Health Sci. 2011:21(3):167-74.

29. Mazigo DH, Waihenya R, Mkoji MG, Zinga M, Ambrose EE, Jahanpour FO, et al. Intestinal schistosomiasis: prevalence, knowledge, attitude and practices among school children in an endemic area of north western Tanzania. J Rural Trop Public Health. 2010;9:53-60.

30. Abebe N, Erko B, Medhin G, Nega B. Clinico-epidemiological study of schistosomaisis mansoni in Waja-Timuga, District of Alamata, northern Ethiopia. Parasit Vectors. 2014;158(7):1-8.

31. Alemu A, Atnafu A, Addis Z, Shiferaw Y, Teklu T, Mathewos B, et al. Soil transmitted helminths and Schistosoma mansoni infections among school children in Zarima town, northwest Ethiopia. BMC Infect Dis. 2011;11(1):189.

32. Haile S, Golassa L, Mekonnen Z. Prevalence of Schistosoma mansoni and effectiveness of praziquantel in school children in Finchaa valley, Ethiopia. J Parasitol Vect Biol. 2012:4(3):25-30

33. John R, Ezekiel M, Philbert C, Andrew A. Schistosomiasis transmission at high altitude crater lakes in Western Uganda. BMC Infect Dis. 2008:8:110.

34. Assefa A, Dejenie T, Tomass Z. Infection prevalence of Schistosoma mansoni and associated risk factors among schoolchildren in suburbs of Mekelle city, Tigray, Northern Ethiopia. MEJS. 2013;5(1):174-88

35. Legesse M, Erko B. Prevalence of intestinal parasites among schoolchildren in a rural area close to the southeast of Lake Langano, Ethiopia. Ethiop J Health Dev. 2004;18(2):116-20.

36. Dejenie T, Asmelash T, Abdelkadir M. Efficacy of praziquantel in treating Schistosoma mansoni infected school children in Tumuga and Waja, north Ethiopia. MEJS. 2010;2(2):3-11.
37. Picquet M, Vercruysse J, Shaw DJ, Diop M, Ly A. Efficacy of praziquantel against Schistosoma mansoni in northern Senegal. Trans R Soc Trop Med Hyg. 1998;92(1):90-3.

38. Nega B, Svein Gunar G, Fekadu A, Hailu B, Girmay M, Teferi G. Praziquantel side effects and efficacy related to Schistosoma mansoni egg loads and morbidity in primary school children in north-east Ethiopia. Acta Trop. 1999;72(1):53-63.

39. Danso-Appiah A, De Vlas SJ. Interpreting low praziquantel cure rates of Schistosoma mansoni infections in Senegal. Trends Parasitol. 2002;18(3):125-9.

40. Garba A, Lamine MS, Barkiré N, Djibon A, Sofo B, Gouvras AN, et al. Efficacy and safety of two closely spaced doses of praziquantel against Schistosoma haematobium and Schistosoma mansoni and re-infection patterns in school-aged children in Niger. Acta Trop. 2013;128(2):334-44.

41. Hagan P, Coles GC, Kusel JR, Tchuem-Tchuente LA. Schistosomiasis control: keep taking the tablets. Trends Parasitol. 2004;20(2):92-7.

42. Amin MA, Swar M, Kardaman, Elhussein D, Nouman G, Mahmound A, et al. Treatment of pre-school children under 6 years of age for schistosomiasis: safety, efficacy and acceptability of praziquantel. Sud J M Sci. 2012;7(2):67-76

43. Kihara JH, Muhoho N, Njomo D, Mwobobia IK, Josyline K, Mitsui Y, et al. Drug efficacy of praziquantel and albendazole in school children in Mwea Division, Central Province, Kenya. Acta Trop. 2007;102(3):165-71.

44. Degu G, Mengistu G, Jones J. Praziquantel efficacy against schistosomaisis mansoni in schoolchildren in north-west Ethiopia. Trans R Soc Trop Med Hyg. 2002;96(4):444-5.

\section{Submit your next manuscript to BioMed Central and we will help you at every step:}

- We accept pre-submission inquiries

- Our selector tool helps you to find the most relevant journal

- We provide round the clock customer support

- Convenient online submission

- Thorough peer review

- Inclusion in PubMed and all major indexing services

- Maximum visibility for your research

Submit your manuscript at www.biomedcentral.com/submit
) Biomed Central 